\title{
Influence of Solution Conductivity on Contact Glow Discharge Electrolysis
}

\author{
Xing-Long Jin $\cdot$ Xiao-Yan Wang $\cdot$ Hong-Mei Zhang • \\ Qing Xia $\cdot$ Dong-Bin Wei $\cdot$ Jun-Jie Yue
}

Received: 11 December 2009/Accepted: 18 February 2010/Published online: 5 March 2010

(C) Springer Science+Business Media, LLC 2010

\begin{abstract}
Using a thin platinum anode in contact with an electrolytic solution, normal electrolysis develops spontaneously to contact glow discharge electrolysis (CGDE) at sufficiently high voltage. During this transition, midpoint voltage $\left(\mathrm{V}_{\mathrm{D}}\right)$ is an important critical value. From $V_{D}$ on, plasma is sustained by direct current glow discharge between the electrode and the electrolyte surface. And $\mathrm{H}_{2} \mathrm{O}_{2}$ is the main non-faradaic yield. In this study, effects of conductivity on $\mathrm{V}_{\mathrm{D}}$ and the concentration of $\mathrm{H}_{2} \mathrm{O}_{2}$ have been investigated in $\mathrm{Na}_{2} \mathrm{SO}_{4}$ and $\mathrm{NaCl}$ solution. The results indicate that $\mathrm{V}_{\mathrm{D}}$ decreases with the increasing conductivity. And the value of $\mathrm{V}_{\mathrm{D}}$ and the concentration of $\mathrm{H}_{2} \mathrm{O}_{2}$ in $\mathrm{NaCl}$ solution are less than those in $\mathrm{Na}_{2} \mathrm{SO}_{4}$ solution. The concentration of $\mathrm{H}_{2} \mathrm{O}_{2}$ increases steadily and then decreases to maintain a stationary value.
\end{abstract}

Keywords Contact glow discharge electrolysis · Conductivity · Midpoint voltage . Hydrogen peroxide

\section{Introduction}

Electrochemical discharge phenomenon was first described in literature more than 150 years ago [1]. It is also termed in literature as plasma electrolysis [2], electrode effects [3-6] (anode or cathode effects depending on which electrode the phenomena takes place) or contact glow discharge electrolysis (CGDE) [7-9]. There have been extensive studies on electrochemical discharge because of increasing interest for its application. Nowadays, electrochemical discharge has been used in a variety of fields such as hydrogen production

\footnotetext{
X.-L. Jin $(\bowtie) \cdot$ X.-Y. Wang · H.-M. Zhang · Q. Xia · J.-J. Yue

School of Environmental Science and Safety Engineering, Tianjin University of Technology, 300384 Tianjin, People's Republic of China

e-mail: xljin7911@126.com

D.-B. Wei

State Key Laboratory of Environmental Chemistry and Ecotoxicology, Research Center for Eco-Environmental Sciences, Chinese Academy of Sciences, 100085 Beijing,

People's Republic of China
} 
[10], micro-machining [11], nanoparticle synthesis [12], wastewater treatment $[13,14]$ and so on.

In recent years, much attention has been paid to CGDE for its simpler equipment and operation. In CGDE, plasma is sustained by direct current glow discharge between the electrode and the electrolyte surface [7-9]. Using a thin platinum anode in contact with an electrolytic solution, the conventional normal electrolysis develops spontaneously to CGDE if the applied voltage is raised to a critical value called the midpoint voltage $\left(\mathrm{V}_{\mathrm{D}}\right)$ [15]. CGDE involves normal electrolysis, solvent vaporization near an electrode by Joule heating, hydrodynamic instabilities with vapor sheathing the electrode and glow discharges across the vapor sheath [8].

Chemical yields of anodic CGDE originate from the primary reaction zones, which consist of the plasma around the anode and the liquid phase near the plasma-anolyte interface. In the reaction zone within the plasma around the anode, $\mathrm{H}_{2} \mathrm{O}$ vapor molecules are ionized or activated, and then bombarded each other to break up by charge transfer. The ultimate result is the production of free $\cdot \mathrm{OH}$ and $\cdot \mathrm{H}$ radicals. On the other hand, in the liquid-phase reaction zone near the plasma-anolyte interface, several liquid $\mathrm{H}_{2} \mathrm{O}$ molecules break up into $\mathrm{H}_{2}$ and $\mathrm{H}_{2} \mathrm{O}_{2}$ plus $\mathrm{O}_{2}$ by being bombarded by each $\mathrm{H}_{2} \mathrm{O}_{\text {gas }}^{+}$from the anodic plasma $[8,15]$. As a mixture of these active species, $\cdot \mathrm{OH}, \cdot \mathrm{H}, \mathrm{H}_{2} \mathrm{O}_{2}$ and $\mathrm{H}_{2} \mathrm{O}_{\text {gas }}^{+}$diffuse out of the primary zone and into the bulk electrolyte. They can interact among themselves and with any active substrate in the solution. Consequently, CGDE can be used to induce some unusual chemical changes in the solution.

Although CGDE has been systematically investigated in recent years, some issues remain unclear. For example, Hickling [16] concluded that the value of $V_{D}$ was $410 \mathrm{~V}$; while Susanta et al. [15] reported that $V_{D}$ was $420 \mathrm{~V}$, which was unaffected by the electrolyte's composition, concentration, temperature and surface tension. The effects of conductivity on the value of $\mathrm{V}_{\mathrm{D}}$ and non-faradaic yield $\left(\mathrm{H}_{2} \mathrm{O}_{2}\right)$ have not been investigated. In this study, we did a series of experiments to address these problems.

\section{Experimental}

Experimental apparatus was shown in Fig. 1. The anode was a platinum wire $(0.3 \mathrm{~mm})$ held in the brass support sealed into a glass tube. The cathode was a stainless steel stick placed in another glass tube ( $5 \mathrm{~cm}$ diameter), which was covered at the bottom by a sinter glass disk of medium porosity. Dissolved oxygen was removed from the electrolyte. The platinum wire was immersed into the solution to a depth of approximately $1.0 \mathrm{~mm}$. In addition, the reaction cell was placed in a temperature-controlled water bath and the temperature of electrolyte was remained at $30^{\circ} \mathrm{C}$. Electrolytic solutions with certain conductivity were prepared by dissolving sodium sulfate or sodium chloride in the distilled water. The solution was gently stirred with a magnet bar during the reaction. The pressure in the reactor was atmospheric. The voltage was applied through a direct current power supply (variable voltage $0-1,000 \mathrm{~V}$ and current 0-300 mA).

A Cary $50 \mathrm{UV}$-vis spectrometer (Varian, America) was used to determine the concentration of $\mathrm{H}_{2} \mathrm{O}_{2}$ in the process of CGDE. The determination of $\mathrm{H}_{2} \mathrm{O}_{2}$ was based on the reaction of $\mathrm{H}_{2} \mathrm{O}_{2}$ with titanyl ions giving yellow-colored complex of pertitanic acid [17]:

$$
\mathrm{Ti}^{4+}+\mathrm{H}_{2} \mathrm{O}_{2}+2 \mathrm{H}_{2} \mathrm{O} \rightarrow \mathrm{TiO}_{2} \cdot \mathrm{H}_{2} \mathrm{O}_{2}+4 \mathrm{H}^{+}
$$


Fig. 1 Schematic diagram of the CGDE reactor a glass tube;

b cathode; c anode; $\mathbf{d}$ water bath; e electrolytic solution; f magnetic bar; $\mathbf{g}$ gas outlet and sampling port

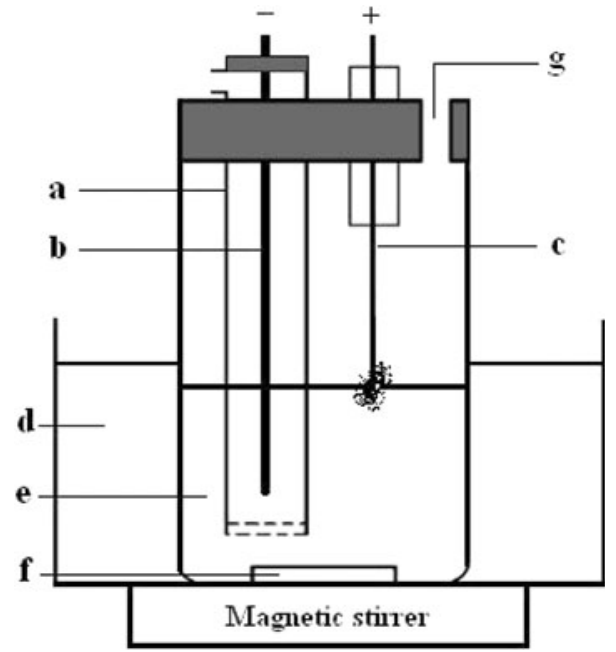

\section{Results and Discussion}

\section{I-V Characteristic}

A series of experiment was conducted in sodium sulfate solution to investigate the characteristic of anodic CGDE. I-V (Current vs. Voltage) curve was shown in Fig. 2, and four different regions were obviously identified. In section $\mathrm{AB}$, the current was approximately in proportion to the applied voltage. Ohm's law was obeyed in section $\mathrm{AB}$ and conventional electrolysis occurred with small bubbles of gas leaving the anode. When the voltage continued increasing, a sharp decrease was observed at point B and the trend was maintained in $\mathrm{BC}$ region, with current being inverse proportional to the applied voltage. In this region, bubbles adhered to the anode surface and insulated a fraction of the surface, making it inactive. When the bubbles underwent the process of formation and collapse, the oscillation of the current occurred. At point $\mathrm{C}$, the stabilized vapor sheath appeared around the anode. In section $\mathrm{CD}$, the compact vapor sheath built up around the anode and progressively covered the anode surface. Current continued to slow down, reaching minimum at point $\mathrm{D}$. From point $\mathrm{D}$ on, the current started to increase steadily with the rising voltage

Fig. 2 I-V curve (Medium: $\mathrm{Na}_{2} \mathrm{SO}_{4}$; conductivity: $2.92 \mathrm{mS} \mathrm{cm}^{-1}$ )

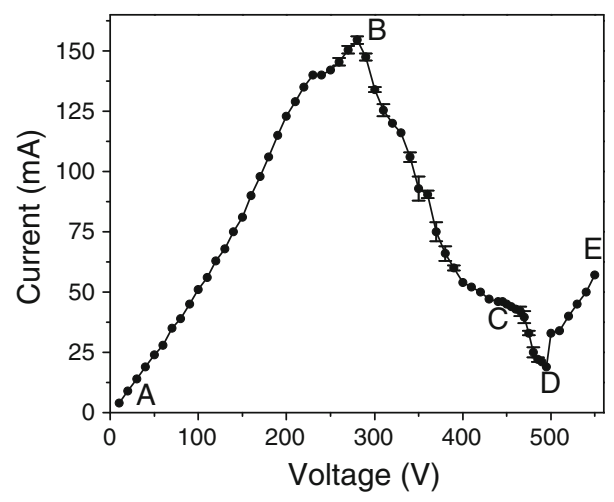

Springer 
Fig. 3 I-V curve (Medium:

$\mathrm{NaCl}$; conductivity:

$2.93 \mathrm{mS} \mathrm{cm}^{-1}$ )

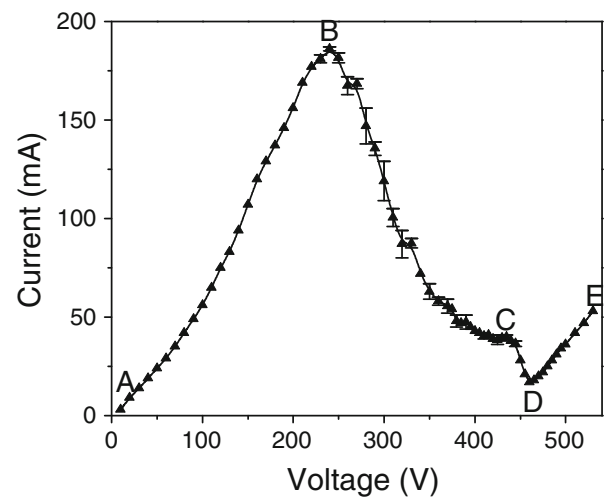

and violet glow appeared in the anode. In section DE, glow discharge became yellow. The voltage at point $\mathrm{D}$ was called the midpoint voltage $\left(\mathrm{V}_{\mathrm{D}}\right)$ [15].

The CGDE experiment was also conducted in $\mathrm{NaCl}$ solution. Its initial conductivity was close to that of $\mathrm{Na}_{2} \mathrm{SO}_{4}$ solution. I-V characteristic of CGDE in $\mathrm{NaCl}$ solution was shown in Fig. 3 and the curve pattern was similar to that in $\mathrm{Na}_{2} \mathrm{SO}_{4}$ solution. However, the current fluctuation was more obvious in $\mathrm{NaCl}$ solution in section $\mathrm{BC}$. The current at point $\mathrm{B}$ was higher than that of $\mathrm{Na}_{2} \mathrm{SO}_{4}$ solution. $\mathrm{V}_{\mathrm{D}}(460 \mathrm{~V})$ in $\mathrm{NaCl}$ solution was less than that $(495 \mathrm{~V})$ in $\mathrm{Na}_{2} \mathrm{SO}_{4}$ solution, though.

\section{Effect of Conductivity on $\mathrm{V}_{\mathrm{D}}$}

To investigate the effect of conductivity on $\mathrm{V}_{\mathrm{D}}$, CGDE was conducted in $\mathrm{Na}_{2} \mathrm{SO}_{4}$ solution with its conductivity changing from 0.91 to $8.66 \mathrm{mS} \mathrm{cm}^{-1}$. As seen in Fig. $4, \mathrm{~V}_{\mathrm{D}}$ clearly decreased, from 570 to $425 \mathrm{~V}$, with the increase of conductivity in $\mathrm{Na}_{2} \mathrm{SO}_{4}$ solution. The result was connected with the characteristic at point $\mathrm{D}$, where the vapor sheath covered the anode and current transport happened through glow discharge. At point $\mathrm{D}$, the critical factor for the onset of glow discharge across the vapor sheath was a sufficient potential drop to cause an appreciable conduction through the gas phase. When the conductivity of the electrolyte increased, the ion migration was enhanced and relatively lower voltage could sustain sufficient potential drop. Therefore, $V_{D}$ decreased with the increase of conductivity.

Fig. 4 Variation of $V_{D}$ with conductivity of solution

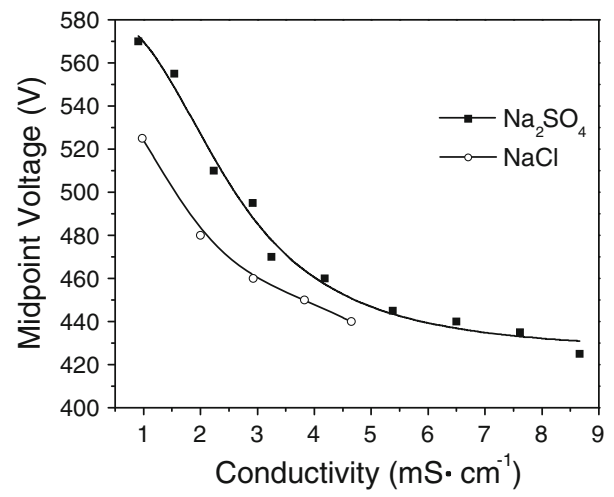


Fig. 5 Variation of $\mathrm{pH}$ and conductivity in $\mathrm{Na}_{2} \mathrm{SO}_{4}$ and $\mathrm{NaCl}$ solution in CGDE (Voltage: $500 \mathrm{~V}$ )

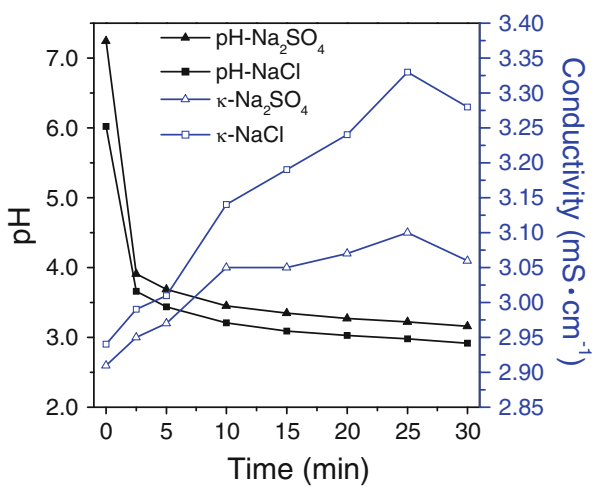

The CGDE experiments were also conducted in $\mathrm{NaCl}$ solution with its conductivity in the range of $0.97-4.65 \mathrm{mS} \mathrm{cm}{ }^{-1}$. $\mathrm{V}_{\mathrm{D}}$ changed from 525 to $440 \mathrm{~V}$, as shown in Fig. $4 . \mathrm{V}_{\mathrm{D}}$ also decreased with the increasing conductivity and the trend was similar to that in $\mathrm{Na}_{2} \mathrm{SO}_{4}$ solution. However, $\mathrm{V}_{\mathrm{D}}$ in $\mathrm{NaCl}$ solution was lower than those in $\mathrm{Na}_{2} \mathrm{SO}_{4}$ solution, even though the initial conductivity of two solutions was the same. That is, $\mathrm{V}_{\mathrm{D}}$ was affected by the electrolyte's composition and concentration, which was different from those reported previously [15].

Figure 5 displayed the change of $\mathrm{pH}$ and conductivity in $\mathrm{Na}_{2} \mathrm{SO}_{4}$ and $\mathrm{NaCl}$ solution in CGDE. The $\mathrm{pH}$ of $\mathrm{NaCl}$ solution was less than that of $\mathrm{Na}_{2} \mathrm{SO}_{4}$ solution, while the conductivity of $\mathrm{NaCl}$ solution was higher than that of $\mathrm{Na}_{2} \mathrm{SO}_{4}$ solution in the process of CGDE. A possible explanation was that the following reactions occurred.

$$
\begin{gathered}
\cdot \mathrm{OH}+\mathrm{Cl}^{-} \rightarrow \mathrm{Cl}+\mathrm{OH}^{-} \\
\mathrm{Cl} \cdot+\mathrm{Cl} \cdot \rightarrow \mathrm{Cl}_{2} \\
\mathrm{Cl}_{2}+\mathrm{H}_{2} \mathrm{O} \rightarrow \mathrm{HCl}+\mathrm{HClO} \\
2 \mathrm{HClO}+\mathrm{H}_{2} \mathrm{O}_{2} \rightarrow 2 \mathrm{Cl}^{-}+\mathrm{O}_{2}+2 \mathrm{H}^{+}
\end{gathered}
$$

When $\mathrm{CGDE}$ was performed in $\mathrm{NaCl}$ solution, $\mathrm{Cl}^{-}$could be transformed to chlorine radical. Two chlorine radicals reacted with each other to form one molecular of chlorine. $\mathrm{HClO}$ formed in reaction (4) then reacted with $\mathrm{H}_{2} \mathrm{O}_{2}$ to produce $\mathrm{H}^{+}[18,19]$. The concentration of $\mathrm{H}^{+}$in $\mathrm{NaCl}$ solution was higher than that in $\mathrm{Na}_{2} \mathrm{SO}_{4}$ solution during the process of CGDE, even when the initial conductivity was the same. Because the ionic mobility of $\mathrm{H}^{+}$was much higher than other ions, $\mathrm{NaCl}$ solution has a higher conductivity than $\mathrm{Na}_{2} \mathrm{SO}_{4}$ solution during the process of CGDE. Therefore, even starting with the same initial conductivity, $\mathrm{V}_{\mathrm{D}}$ in $\mathrm{NaCl}$ solution was less than that in $\mathrm{Na}_{2} \mathrm{SO}_{4}$ solution during the process of CGDE.

Effect of Conductivity on the Concentration of $\mathrm{H}_{2} \mathrm{O}_{2}$

$\mathrm{H}_{2} \mathrm{O}_{2}$ was the main non-faradaic product in CGDE. The measurement of $\mathrm{H}_{2} \mathrm{O}_{2}$ was useful to those reactions utilizing $\mathrm{H}_{2} \mathrm{O}_{2}$ in CGDE. The concentration of $\mathrm{H}_{2} \mathrm{O}_{2}$ was determined with the increasing voltage in $\mathrm{Na}_{2} \mathrm{SO}_{4}$ solution and the result was shown in Fig. 6. It was found that $\mathrm{H}_{2} \mathrm{O}_{2}$ started to form near $450 \mathrm{~V}$ and underwent a sharp rise after $495 \mathrm{~V} .495 \mathrm{~V}$ was none other than the value of $\mathrm{V}_{\mathrm{D}}$ on this condition. That is to say, $\mathrm{H}_{2} \mathrm{O}_{2}$ with higher 
Fig. 6 Variation of $\mathrm{H}_{2} \mathrm{O}_{2}$ with increasing voltage in $\mathrm{CGDE}$ $\left(\mathrm{Na}_{2} \mathrm{SO}_{4}: 2.92 \mathrm{mS} \mathrm{cm}^{-1}\right)$

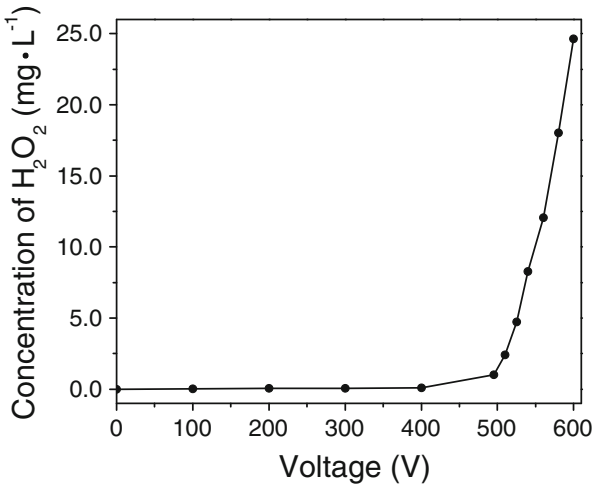

Fig. 7 The concentration of $\mathrm{H}_{2} \mathrm{O}_{2}$ in $\mathrm{Na}_{2} \mathrm{SO}_{4}$ and $\mathrm{NaCl}$ solution (Voltage: $500 \mathrm{~V}, \mathrm{NaCl}$ : $2.93 \mathrm{mS} \mathrm{cm}{ }^{-1}, \mathrm{Na}_{2} \mathrm{SO}_{4}$ : $2.92 \mathrm{mS} \mathrm{cm}^{-1}$ )

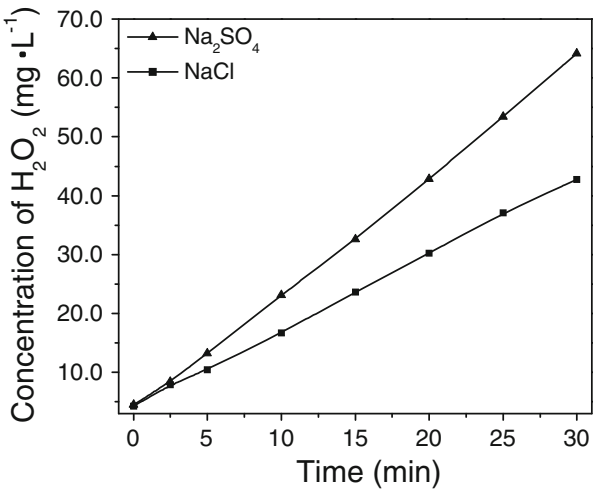

concentration was formed only when the voltage was beyond the value of $\mathrm{V}_{\mathrm{D}}$. So, $500 \mathrm{~V}$ is chosen as the applied voltage in the subsequent study, which was higher than $V_{D}$ of each electrolyte.

The concentration of $\mathrm{H}_{2} \mathrm{O}_{2}$ in $\mathrm{Na}_{2} \mathrm{SO}_{4}$ solution and $\mathrm{NaCl}$ solution was also determined during CGDE, which was shown in Fig. 7. $\mathrm{H}_{2} \mathrm{O}_{2}$ accumulating in anolyte increased linearly with the treatment time of CGDE. The concentration of $\mathrm{H}_{2} \mathrm{O}_{2}$ in $\mathrm{NaCl}$ solution was less than that in $\mathrm{Na}_{2} \mathrm{SO}_{4}$ solution, as expected based on our previous explanation. When CGDE was performed in $\mathrm{NaCl}$ solution, $\mathrm{HClO}$ consumed $\mathrm{H}_{2} \mathrm{O}_{2}$ accumulating in the solution, therefore causing the decrease of $\mathrm{H}_{2} \mathrm{O}_{2}$ concentration.

We also studied the effect of conductivity on the formation of $\mathrm{H}_{2} \mathrm{O}_{2}$ by measuring the concentration of $\mathrm{H}_{2} \mathrm{O}_{2}$ in $\mathrm{Na}_{2} \mathrm{SO}_{4}$ solution with the conductivity changing from 2.92 to $7.61 \mathrm{mS} \mathrm{cm}{ }^{-1}$. As shown in Fig. 8, higher conductivity caused more production of $\mathrm{H}_{2} \mathrm{O}_{2}$ at the beginning of CGDE. The concentration of $\mathrm{H}_{2} \mathrm{O}_{2}$ was approximately in proportion to the conductivity of solution. After 10 min treatment of CGDE, the concentration of $\mathrm{H}_{2} \mathrm{O}_{2}$ was highest in $7.61 \mathrm{mS} \mathrm{cm}{ }^{-1} \mathrm{Na}_{2} \mathrm{SO}_{4}$ solution. However, with the treatment time increasing to $20 \mathrm{~min}$, the relationship between concentration of $\mathrm{H}_{2} \mathrm{O}_{2}$ and the conductivity changed. The concentration of $\mathrm{H}_{2} \mathrm{O}_{2}$ increased steadily and then decreased to maintain a stationary value. The highest amount of $\mathrm{H}_{2} \mathrm{O}_{2}$ was formed in $5.38 \mathrm{mS} \mathrm{cm}{ }^{-1} \mathrm{Na}_{2} \mathrm{SO}_{4}$ solution. We reasoned that when the applied voltage $(500 \mathrm{~V})$ and the conductivity of solution was $2.92 \mathrm{mS} \mathrm{cm}^{-1}$, plasma was not fully formed and the amount of reactive species produced was not enough. However, when the conductivity increased to $7.61 \mathrm{mS} \mathrm{cm}^{-1}, \mathrm{~V}_{\mathrm{D}}$ decreased. Plasma 
Fig. 8 Variation of concentration of $\mathrm{H}_{2} \mathrm{O}_{2}$ with conductivity of $\mathrm{Na}_{2} \mathrm{SO}_{4}$ solution

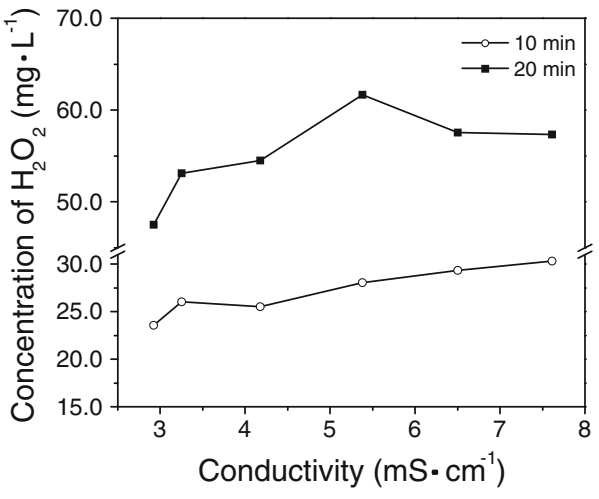

became full and sufficient $\mathrm{H}_{2} \mathrm{O}_{2}$ accumulated in anolyte, and underwent decomposition to $\mathrm{O}_{2}^{\mathrm{E}}$ due to its further reaction with $\cdot \mathrm{OH}[15]$.

$$
\begin{gathered}
\cdot \mathrm{OH}+\mathrm{H}_{2} \mathrm{O}_{2} \rightarrow \mathrm{H}_{2} \mathrm{O}+\mathrm{HO}_{2} \cdot \quad \mathrm{k}_{1}=4.5 \times 10^{7} \mathrm{M}^{-1} \mathrm{~s}^{-1} \\
2 \mathrm{HO}_{2} \cdot \rightarrow \mathrm{H}_{2} \mathrm{O}_{2}+\mathrm{O}_{2} \quad \mathrm{k}_{2}=8.3 \times 10^{5} \mathrm{M}^{-1} \mathrm{~s}^{-1} \\
\mathrm{HO}_{2}+\mathrm{H}_{2} \mathrm{O}_{2} \rightarrow \cdot \mathrm{OH}+\mathrm{H}_{2} \mathrm{O}+\mathrm{O}_{2} \quad \mathrm{k}_{3}=3.0 \mathrm{M}^{-1} \mathrm{~s}^{-1}
\end{gathered}
$$

When the formation and decomposition of $\mathrm{H}_{2} \mathrm{O}_{2}$ reached balance, the concentration of $\mathrm{H}_{2} \mathrm{O}_{2}$ finally maintained at a stationary value. For those reactions utilizing $\mathrm{H}_{2} \mathrm{O}_{2}$ in CGDE, the optimum conductivity of $\mathrm{Na}_{2} \mathrm{SO}_{4}$ was around $5.38 \mathrm{mS} \mathrm{cm}^{-1}$ since the highest amount of $\mathrm{H}_{2} \mathrm{O}_{2}$ was formed at that point.

\section{Conclusions}

$V_{D}$ was affected by the electrolyte's composition and concentration. And $V_{D}$ decreased with the increasing conductivity of solution. Higher amount of $\mathrm{H}_{2} \mathrm{O}_{2}$ was formed only when the applied voltage was above $\mathrm{V}_{\mathrm{D}} \cdot \mathrm{V}_{\mathrm{D}}$ and the concentration of $\mathrm{H}_{2} \mathrm{O}_{2}$ in $\mathrm{NaCl}$ solution were less than those in $\mathrm{Na}_{2} \mathrm{SO}_{4}$ solution. The concentration of $\mathrm{H}_{2} \mathrm{O}_{2}$ increased steadily with the increasing conductivity, and then decreased to maintain a stationary value. The concentration of $\mathrm{H}_{2} \mathrm{O}_{2}$ in $5.38 \mathrm{mS} \mathrm{cm}{ }^{-1} \mathrm{Na}_{2} \mathrm{SO}_{4}$ solution was found to be the highest.

Acknowledgments This work was supported by the National Nature Science Foundation of China (20807030). The authors would like to thank the National High Technology Research and Development Program of China (2007AA06Z338) and the Open Foundation of State Key Laboratory of Environmental Chemistry and Ecotoxicology, Research Center for Eco-Environmental Sciences, Chinese Academy of Sciences (KF2008-10).

\section{References}

1. Wüthrich R, Mandin P (2009) Electrochim Acta 54:4031-4035

2. Mizuno T, Akimoto T, Azuni K, Ohmori T, Aoki Y, Takahashi A (2005) Jpn J Appl Phys 44(1A): 396-401

3. Wüthrich R, Fascio V, Bleuler H (2004) Electrochim Acta 49:4005-4010 
4. Wüthrich R, Comninellis CH, Bleuler H (2005) Electrochim Acta 50:5242-5246

5. Vogt H (1997) Eiectrochimica Acta 42(17):2695-2705

6. Vogt H (1999) J Appl Electrochem 29:137-145

7. Sengupta SK, Singh OP (1991) J Electroanal Chem 30:189-197

8. Sengupta SK, Singh OP (1994) J Electroanal Chem 369:113-120

9. Sengupta SK, Srivastava AK, Singh R (1997) J Electroanal Chem 42:23-27

10. Yan Z-C, Chen L, Wang H-L (2009) Int J Hyd Energ 34:48-55

11. Wüthrich R, Fascio V (2005) Int J Mach Tools Manuf 45:1095-1108

12. Lal A, Bleuler H, Wüthrich R (2008) Electrochem Commun 10:488-491

13. Tezuka M, Iwasaki M (1998) Thin Solid Films 316:123-127

14. Wang L, Jiang X-Z (2008) Environ Sci Technol 42:8492-8497

15. Sengupta SK, Singh R, Srivastava AK (1998) J Electrochem Soc 145:2209-2213

16. Hickling A, Ingram MD (1964) Trans Faraday Soc 60:783-793

17. Eisenberg GM (1943) Ind Eng Chem Res 15:327-328

18. Lukes P, Appleton AT, Locke BR (2002) Conf Rec IEEE 37:1816-1821

19. Aubry JM (1985) J Am Chem Soc 107:5844-5849 